\title{
Processos físicos e químicos para o tratamento de efluentes: uma revisão integrativa
}

\section{Paulo Gabriel Ferreira de Azevedo ${ }^{1}$, Débora Carvalho da Silva Oliveira ${ }^{2}$ e Luiz Antonio Pimentel Cavalcanti ${ }^{2}, *$}

${ }^{1}$ Instituto Federal de Educação, Ciência e Tecnologia da Bahia. Curso de Engenharia Química. Campus Salvador. Rua Emídio dos Santos S/№. Bairro do Barbalho. Salvador-BA, Brasil (CEP 40301-015).

${ }^{2}$ Instituto Federal de Educação. Ciência e Tecnologia da Bahia. Campus Salvador. Rua Emídio dos Santos S/№. Bairro de Barbalho. Salvador-BA, Brasil (CEP 40301-015).*E-mail: luiz.cavalcanti@ifba.edu.br.

Resumo. 0 aumento da produção industrial, provocado pelo crescimento da população mundial, tem gerado uma maior carga de poluentes, dentre eles, os efluentes, comprometendo recursos hídricos. A fim de mitigar os impactos ao meio ambiente, métodos de tratamentos de efluentes têm sido amplamente estudados, sendo os físicos (adsorção, coagulação/floculação) e os químicos (processos oxidativos) os principais. 0 presente trabalho traz uma revisão integrativa e principais resultados encontrados na literatura especializada para esses métodos, no tratamento de diversos tipos de efluentes. Diante disso, esse trabalho poderá servir de base para fundamentação teórica para pesquisas sobre tratamentos de efluentes, uma vez que foram reunidos e discutidos conceitos e resultados acerca destes tratamentos.

Palavras-chave: Tratamento de efluentes; Adsorção; Coagulação/floculação; Processos oxidativos avançados.

Abstract. Physical-chemical processes for effluents treatments: An integrative review. The increase in industrial production, caused by increase in the world population, has generated a great pollutants load, among them, the effluents, compromising the hidrics resources. In order to mitigate impacts on the environment, effluent treatment methods have been widely studied, with physical (adsorption, coagulation/flocculation) and chemical (oxidative processes) being one of the main ones. The present paper brings an integrative review and main results found in the specialized literature for these methods, in the treatment of different types of effluents. Therefore, this work may serve as a basis for theoretical fundamentation in research about the effluents treatment, since concepts and results about these treatments were gathered and discussed.

Keywords: Effluent treatment; Adsorption; Coagulation/ flocculation; Advanced oxidative processes.
Recebido

$09 / 11 / 2020$

Aceito

$20 / 12 / 2020$

Disponível on line

$23 / 12 / 2020$

Publicado

$31 / 12 / 2020$

Acesso aberto

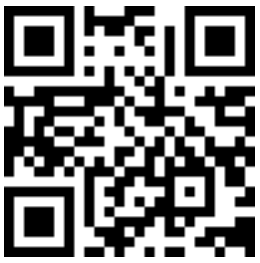

ORCID

(D) 0000-0003-0685-2928 Paulo Gabriel Ferreira de Azevedo

0000-0003-0987-724X Débora Carvalho da Silva Oliveira

D) 0000-0003-4932-9387 Luiz Antonio Pimentel Cavalcanti

ISSN 2359-1412/RBGAS-2020-0166/2020/7/17/40/1667

Rev. Bras. Gest. Amb. Sustent.

http://revista.ecogestaobrasil.net 


\section{Introdução}

Segundo dados do Worldometer (2020), a população mundial partiu de aproximadamente 2,6 bilhões, em 1951, para 7,7 bilhões até 2019 , um aumento de quase $296 \%$. Juntamente com esse expressivo aumento da população, percebe-se, também, a ampliação da atividade industrial ao redor do globo; gerando, com isso, uma maior carga de subprodutos e efluentes (Silva Neto et al., 2020). Segundo o Ministério do Meio Ambiente (MMA, 2015), o Brasil detém o volume de água por habitante superior ao recomendado pela Organização das Nações Unidas; no entanto, o mesmo ministério também adverte sobre a possibilidade de esgotamento dessa reserva. Proporcionada pelo aumento das atividades industriais, o descarte indevido de efluentes em corpos hídricos compromete a qualidade da água, contribuindo para o esgotamento dessa reserva (Gomes et al., 2018; Abreu et al., 2019).

A normatização do descarte de efluentes no Brasil é realizada pelo Conselho Nacional do Meio Ambiente (CONAMA), por meio da Resolução no 430/2011 (Brasil, 2011), onde alguns parâmetros como composição química inorgânica, pH e demanda bioquímica de oxigênio (DBO) são regulamentados, além da resolução servir como referência quando se trata de tratamento de efluentes visando o alcance desses parâmetros. Segundo Morais et al. (2019), a legislação supracitada contribui para identificação de possíveis infringentes dos padrões aceitáveis de descarte de efluentes, facilita a fiscalização e auxilia na conservação desses meios.

Com o intuito de regularizar os parâmetros físicos e químicos dos efluentes, objetivando o descarte apropriados desses subprodutos, propõe-se submeter esses resíduos aos chamados tratamentos de efluentes. Kamali et al. (2019) ressaltaram que o quantitativo de poluentes contidos nos efluentes depende de inúmeras variáveis do processo, bem como do estágio desse processo em que esse resíduo é gerado. Os mesmos autores, apontam a necessidade dos tratamentos serem suficientemente eficientes, ao mesmo tempo que consideram fatores econômicos e ambientais.

Diante da diversidade de resíduos gerados pelas atividades antropológicas, variados tipos de tratamentos são empregados conforme a necessidade e características do efluente. Os principais tipos de tratamentos relatados na literatura são os físicoquímicos (adsorção, agregação, oxidativos entre outros) e biológicos, com destaque recente para os chamados Processos Oxidativos Avançados (POA) (Külzer e Rodrigues, 2016). Os métodos citados costumam ser adotados sequencialmente, isto é, o efluente inicialmente é tratado físico-quimicamente, para redução do excesso de poluentes, seguido do tratamento biológico, com possíveis intervenções finais, a depender das características do despejo a ser tratado (Rocha et al., 2016).

Diante da importância dos tratamentos de efluentes, o presente trabalho visa a fazer uma revisão bibliográfica sobre os métodos físico-químicos e biológicos, apontando características genéricas e resultados da literatura.

\section{Metodologia}

0 presente trabalho seguiu o delineamento de revisão integrativa, para isso, foi realizado um levantamento minucioso da literatura relacionada nas plataformas Scielo e google scholar usando os descritores "tratamento de efluentes", "tratamento físicoquímicos", "efluentes industriais" e "tratamentos biológicos", utilizando como critérios de inclusão todos os artigos que retratavam os principais tratamentos de efluentes empregados para mitigação de poluentes em cursos hídricos e como critérios de exclusão todos os artigos de divergiam do tema. 


\section{Resultados e discussão}

0 processo de tratamento de efluentes via adsorção é definida pela interação de moléculas, de um meio líquido ou gasoso, na superfície de um sólido, sendo o primeiro chamado de adsorbato e o último de adsorvente, tendo como causa o desbalanceamento das forças intermoleculares que há entre as substâncias do adsorvente em sua superfície. A depender do tipo de interação entre o adsorbato e o adsorvente, o mecanismo de adsorção pode ser chamado de quimissorção ou fisissorção, sendo o primeiro caracterizado pela interação química entre adsorbato e adsorvente, e o segundo por uma interação física entre as partes mencionadas (Nascimento et al., 2019).

Nos métodos de adsorção, é comum o emprego de sólidos porosos, cujo mecanismo pode ser descrito em etapas: difusão do adsorbato do seio do fluido até adentrar na camada limite formada pelo sólido (adsorvente), difusão dentro da camada limite formada pelo sólido até o limite de entrada do poro do adsorvente, difusão do adsorbato dentro do poro do adsorvente até os sítios de adsorção, gerando o contato entre o adsorbato e adsorvente, onde ocorre a adsorção. 0 processo inverso é chamado de dessorção (Kieling, 2016). Os processos de transferências de massa que ocorrem dentro e fora dos poros do adsorvente diferenciam-se devido ao coeficiente de transferência de massa (Nascimento et al., 2019).

Referindo-se ao processo de adsorção na remoção de poluentes, Kieling (2016) estudou o uso de cinzas de casca de arroz, além do carvão ativado, como adsorvente, objetivando a remoção de benzeno, tolueno, etilbenzeno e xileno. Na perspectiva de contribuir para o reaproveitamento de um resíduo, o estudo com cinzas de casca de arroz como adsorvente é justificado pelo fato do uso do carvão ativado, apesar de amplamente utilizado, ser dispendioso, segundo a autora. Desse trabalho, concluiu-se que os adsorventes atuam eficientemente no processo de remoção dos poluentes estudados, com resultados variando entre $78,8 \%$ e $100 \%$ para a cinza de casca de arroz e $91,6 \%$ e $100 \%$ para o carvão ativado. Portanto, esse resultado mostra que adsorvente com materiais alternativos são viável no tratamento de efluentes.

Vários fatores influenciam na velocidade e eficiência do processo de adsorção, tal como concentração e natureza do adsorbato, natureza do adsorvente, tamanho dos poros e temperatura. Modelos de pseudo-primeira ordem, pseudo-segunda ordem e difusão interpartículas, Equações 1, 2 e 3, respectivamente, são usados para descrever o fenômeno de adsorção, bem como o emprego de isotermas de adsorção (Kieling, 2016).

$$
\begin{aligned}
& \frac{d q_{t}}{d t}=k_{1}\left(q_{e}-q_{t}\right) \\
& \frac{d q_{t}}{d t}=k_{2}\left(q_{e}-q_{t}\right)^{2} \\
& q_{t}=k_{i n} \sqrt{t}+C
\end{aligned}
$$

Sendo $\mathrm{q}_{\mathrm{e}}$ e $\mathrm{q}_{\mathrm{t}}$ as quantidades adsorvidas no equilíbrio e no tempo $\mathrm{t}$, respectivamente, em $\mathrm{mg} \cdot \mathrm{g}^{-1}$, $\mathrm{t}$ o tempo em min, C uma constante referente a resistência à difusão e $\mathrm{k}_{1}, \mathrm{k}_{2}$ e $\mathrm{k}_{\text {in }}$ as constantes de velocidade de adsorção de pseudo-primeira ordem em min $^{-1}$, pseudo-segunda ordem em $\mathrm{g} \cdot \mathrm{min} \cdot \mathrm{mg}^{-1}$ e de difusão intrapartícula $\mathrm{mg} \cdot \mathrm{min}^{-1} \cdot \mathrm{g}^{-1}$, respectivamente.

A utilização de carvão ativado como adsorvente é bastante comum, no entanto oneroso (Seixas et al., 2016). Por conta disso, diversos estudos têm sido realizados investigando outros materiais adsorventes, geralmente materiais lignocelulósicos são

Rev. Bras. Gest. Amb. Sustent., 2020, vol. 7, n. 17, p. 1667-1678. 
empregados como cinzas de casca de arroz (Kieling, 2016), bagaço de cana-de-açúcar (Seixas et al., 2016) e fibra de coco (Nascimento et al., 2019).

Seixas et al. (2016) basearam sua pesquisa no bagaço de cana-de-açúcar como substância adsorvente e compararam com o carvão ativado. 0 estudo tinha como objetivo o tratamento da vinhaça, efluente altamente poluente gerado pela produção do etanol. Para isso, os autores utilizaram os carvões resultantes da carbonização do bagaço de canade-açúcar nas temperaturas de $400^{\circ} \mathrm{C}, 500^{\circ} \mathrm{C}, 600^{\circ} \mathrm{C}, 700^{\circ} \mathrm{C}$ e $800^{\circ} \mathrm{C}$, com e sem ativação com hidróxido de sódio $(\mathrm{NaOH})$ e carvão ativado comercial, isto é, um total de 11 condições distintas de adsorventes. Tanto para a remoção de cor, como de turbidez, os melhores resultados foram para o adsorvente carbonizado a $800{ }^{\circ} \mathrm{C}$ sem tratamento químico, sendo 50,5\% e $83,0 \%$ as porcentagens de remoção de cor e turbidez, respectivamente. Em contrapartida, os menores resultados são para o adsorvente carbonizado a $700{ }^{\circ} \mathrm{C}$, com $28,3 \%$ de remoção de cor, e o carbonizado a $500{ }^{\circ} \mathrm{C}$, com $32,0 \%$ de remoção de turbidez, os dois casos tratam-se de adsorventes quimicamente tratados. Esses resultados mostram, novamente, a viabilidade do emprego de substâncias alternativas como adsorventes em processos de tratamento de efluentes.

0 contato entre o efluente e o material adsorvente é geralmente realizado através de reatores de leito fixo, ou adsorção em coluna, onde o fluido escoa através do adsorvente, ou por diferencial de pressão ou por ação gravitacional (Nascimento et al., 2019).

Os principais tipos de métodos físicos e químicos de agregação são a coagulação e a floculação (Külzer e Rodrigues, 2016). Os métodos de agregação ocorrem sequencialmente, ou seja, inicialmente tem-se a coagulação, seguida da floculação, finalizando com processos de separação física, como sedimentação, filtração, decantação ou flotação (Silva et al., 2019).

A coagulação baseia-se na interação química de um agente coagulante (natural ou químico) com substâncias químicas do efluente, na maioria das vezes corantes, cujas propriedades químicas impedem tanto sua aglomeração como sedimentação, interferindo em atributos de efluente, como cor e turbidez (Ribeiro, 2018). No caso dos corantes, partículas coloidais, sua interação com os agentes coagulantes é explicada devido a formação de uma superfície negativamente carregada, gerando forças de repulsão entre essas partículas (Rubilar, 2017). Sendo os agentes coagulantes cátions, hidrolisados devido ao meio aquoso, eles interagem com as partículas em suspensão de carga negativa, gerando a desestabilização das mesmas, resultando nos coágulos (Ribeiro, 2018).

Substâncias como sais de alumínio e de ferro são amplamente utilizados como agentes coagulantes, assim como hidróxido de sódio $(\mathrm{NaOH})$ ou óxido de cálcio, cal $(\mathrm{CaO})$ (Ribeiro, 2018). Esses são chamados de agentes coagulantes químicos (Miguel et al., 2017). Devido a baixas alterações químicas no $\mathrm{pH}$ do efluente, o sulfato de alumínio $\left(\mathrm{Al}_{2}\left(\mathrm{SO}_{4}\right)_{3}\right)$ é o coagulante mais empregado no Brasil (Silva et al., 2019).

Sobre os agentes usados no processo de coagulação, Ribeiro (2018) estudou quatro tipos distintos de agentes coagulantes no tratamento de efluentes gerados na etapa de curtume, um dos estágios da produção de couro. As substâncias usadas como agentes coagulantes foram $\mathrm{Al}_{2}\left(\mathrm{SO}_{4}\right)_{3}$, cloreto férrico $\left(\mathrm{FeCl}_{3}\right)$, sulfato ferroso $\left(\mathrm{Fe}_{2}\left(\mathrm{SO}_{4}\right)_{3}\right)$ e um composto de policloreto de alumínio, comercialmente chamado de Acquafloc 18. Diante dessa proposta, nota-se a importância do estudo dos agentes de coagulação, de modo a considerar fatores como disponibilidade, custo, eficiência, operacionalidade etc. A autora concluiu que as condições ótimas de tratamento foram atingidas nos ensaios com maiores concentrações dos agentes $\left(1800 \mathrm{mg} \cdot \mathrm{L}^{-1}\right)$ nos quatro casos estudados, a eficiência de remoção de DQO foi maior para o $\mathrm{FeCl}_{3}$, mas o $\mathrm{Al}_{2}\left(\mathrm{SO}_{4}\right)_{3}$ se mostrou mais efetivo nas demais variáveis, como turbidez e pH final. Além disso, foi realizada uma análise de custo para o uso do $\mathrm{Al}_{2}\left(\mathrm{SO}_{4}\right)_{3}$, confirmando a relevância do custo como um fator determinante para escolha e aplicação de um agente coagulante. 
No entanto, também são utilizados agentes coagulantes naturais, como proteínas, tanino, quitina etc., diante de suas vantagens quando comparados com os químicos, principalmente devido à biodegradabilidade (Miguel et al., 2017; Rubilar, 2017), uma vez que os coagulantes químicos, como os empregados por Ribeiro (2018), são questionados quanto sua baixa biodegradabilidade, alta toxicidade e baixa reutilização. Sob essas justificativas, aliado ao baixo custo, Miguel et al. (2017) utilizaram sementes de Moringa oleifera como agente coagulante para redução da turbidez de efluentes gerados por uma lavanderia têxtil. Foram estudados três concentrações de coagulantes: 1,4 g, 2,0 g e 2,5 g de coagulante por $500 \mathrm{~mL}$ de efluente. Nesse estudo, os autores concluíram que a concentração ótima foi de 1,4 g de coagulante por $500 \mathrm{~mL}$ de efluente, com turbidez de $35,6 \%$ da turbidez encontrada para o pior resultado, que foi para a concentração de 2,0 g de coagulante para $500 \mathrm{~mL}$ de efluente. Os mesmos concluíram a viabilidade da implementação dessas sementes como agentes coagulantes, com base nas vantagens frente aos coagulantes químicos.

Diversos trabalhos apontam resultados promissores de tratamentos de efluentes utilizando os métodos de agregação. Nesse contexto, Silva et al. (2019) estudaram os resultados da aplicação de coagulação, floculação e decantação em efluentes gerados pela indústria têxtil. Esse estudo empregou o $\mathrm{Al}_{2}\left(\mathrm{SO}_{4}\right)_{3}$ como agente coagulante nas concentrações de 100, 150 e $200 \mathrm{mg} \cdot \mathrm{L}^{-1}$, com o intuito de analisar a influência desse agente no resultado final. Na etapa de floculação não foram utilizados agentes floculantes, mas a influência da velocidade de agitação do sistema foi investigada. Por fim, o sistema foi mantido sob decantação por $60 \mathrm{~min}$. Os autores concluíram que a maior concentração de $\mathrm{Al}_{2}\left(\mathrm{SO}_{4}\right)_{3}$ e maiores velocidades na etapa de floculação geraram tratamentos mais eficientes. Esse resultado comprova a importância dos agentes coagulantes/floculantes no tratamentos de efluentes via agregação, bem como o sistema de agitação que os promovem.

A floculação é a etapa posterior ao processo de coagulação. Nesse estágio, as partículas já coaguladas, interação entre as partículas coloidais e os agentes coagulantes, interagem entre si formando flocos, sendo que o agente floculante pode ser dispensável (Silva et al., 2019). No caso de ausência de agentes floculantes, o mecanismo desse estágio do método de agregação baseia-se basicamente na agitação lenta do sistema, promovendo o agrupamento das impurezas, formando partículas mais densas, de modo a serem separadas nas etapas posteriores (Rubilar, 2017; Silva et al., 2019). Entretanto, agentes floculantes, como polímeros, podem ser usados para facilitar esse processo; nesse caso, o processo de floculação é facilitado por fenômenos adsortivos que ocorrem devido as interações eletrostáticas entre sítios da cadeia polimérica e as partículas já coaguladas (Ribeiro, 2018).

Por fim, com o intuito de separar os flocos formados no processo de floculação, o efluente é submetido a processos de separação física heterogênea, com destaque para sedimentação e decantação, que se utilizam da diferença de densidade entre o material floculado e a fase líquida e a atuação do campo gravitacional para separação dessas fases, podendo ser seguida da filtração, com o intuito de remover floculados de menor granulometria (Ribeiro, 2018; Rubilar, 2017).

Visando o aperfeiçoamento do método de coagulação, o mesmo tem sido assistido eletroquimicamente, no método chamado eletrocoagulação. Esse procedimento consiste em gerar o agente coagulante in situ, via oxidação do eletrodo de sacrifício, sendo as outras etapas semelhantes ao processo de coagulação (Abreu et al., 2019). Esse sistema é similar ao método tradicional, no entanto a aplicação da corrente elétrica permite geração de íons metálicos, que provém da oxidação do ânodo de sacrifício, e de íons hidroxila, provenientes da eletrólise da água, que interagem entre si e formam compostos capazes de desestabilizar partículas poluentes coloidais, dando origem ao processo de coagulação eletroquímica, isto é, a eletrocoagulação. Com a turbulência, nota-se a formação de flocos, 
etapa chamada de eletrofloculação, onde autores apontaram que os flocos gerados por esse processo são maiores, quando comparados com os flocos formados pela tradicional floculação; facilitando, dessa forma, o processo de separação seguinte, tal com a adsorção, citada nesse trabalho, filtração ou sedimentação (Souza, 2016).

Visto que o aparato experimental dos processos de coagulação/eletrofloculação é mais complexo quando eletroquimicamente auxiliado, estuda-se diversos fatores visando maximizar os resultados desse método de tratamento, sendo os materiais de formam os eletrodos, suas distâncias, a potência elétrica aplicada ao processo e o tempo de reação os mais comuns (Abreu et al., 2019; Andrade et al., 2020). A etapa de oxidação do metal que compõe os eletrodos influencia diretamente na dinâmica de interação entre o íon metálico formado e as partículas poluentes, logo o material que constitui os eletrodos devem ser tais que o potencial elétrico aplicado promova sua oxidação e a geração dos íons metálicos in situ. Isto posto, nota-se que o interesse em se estudar a diversos materiais para servirem de eletrodos em processos de eletrofloculação/eletrocoagulação (Andrade et al., 2020; Souza, 2016). Além do fator do potencial químico, taxa de desgaste, custo e disponibilidade são condições importantes na escolha dos eletrodos (Souza, 2016).

Por ser um processo que necessita de aplicação de energia, o método de eletrofloculação/eletrocoagulação pode ser energeticamente desvantajoso. Por isso, sistemas alternativos de produção de energia, como fotovoltaica, mostram-se importantes nesse cenário, visando ao baixo custo de operação (Vieira et al., 2015).

Nesse viés, Vieira et al. (2015) avaliaram o tratamento de efluentes gerados pela produção de biodiesel de soja, especificamente a água residual originada na etapa de purificação, utilizando um reator eletroquímico com eletrodos constituídos de latas recicladas de alumínio, além da aplicação de energia gerada por placa fotovoltaica para alimentar energeticamente o processo. Foram avaliados efluentes gerados pelas lavagem ácida (ácido clorídrico 0,5 M) e água destilada.

Andrade et al. (2020) investigaram a eficiência da eletrofloculação/ eletrocoagulação no tratamento de amostras de um lago, sob a justificativa de analisar efluentes cada vez mais produzidos com o aumento populacional e de moradias próximas a corpos de água. Já Abreu et al. (2019) centraram seus estudos no tratamento de efluentes gerados na indústria de serigrafia, apontando que métodos como coagulação, floculação e sedimentação, isto é, não assistidas eletroquimicamente, não promovem a remoção satisfatória de cor desses efluentes, tornando a eletrocoagulação uma alternativa mais viável.

Vieira et al. (2015) encontraram resultados aceitáveis em todas as análises, tanto para o efluente da lavagem ácida, como para a de água destilada, com reduções de DQO e $\mathrm{DBO}_{5}$ de cerca de 87 e 94\%, respectivamente, sendo $60 \%$ a exigência de redução mínima de $\mathrm{DBO}_{5}$, prevista na resolução 430/2011 da CONAMA. Além disso, os autores destacaram o uso do sistema de energia fotovoltaica como eficiente para o uso da eletrofloculação/eletrocoagulação, além de ambientalmente amigável. Apesar de alguns resultados não aceitáveis, como o pH em torno de 12.

Abreu et al. (2019) concluíram que os tratamentos via eletrofloculação/ eletrocoagulação exibiram efeitos convincentes para os efluentes originados da serigrafia. Os autores estudaram eletrodos de zinco e latão, objetivando definir o material ideal para constituir os eletrodos, com tempo de reação de $2 \mathrm{~h}$, variação da tensão de 0 a $100 \mathrm{~V}$ e correntes de 3 e 5 A. Foram relatados resultados mais satisfatórios para os ensaios com eletrodos de latão que aqueles obtidos para o zinco, evidenciando a relevância da constituição do eletrodo no processo eletroquímico estudado. Remoção de cor de $96 \%$ foi relatada, para o experimento com eletrodos de latão, com $5 \mathrm{~V}$ de tensão e com adição de 4 $\mathrm{g}$ de cloreto de sódio $(\mathrm{NaCl})$, eletrólito empregado para o aumentar a condutividade elétrica do efluente. Com o propósito de investigar a influência do tempo de reação e da distância entre os eletrodos, nos resultados de pH, turbidez e DQO. 
Andrade et al. (2020) concluíram que as menores distâncias entre os eletrodos $(0,5$ e $1 \mathrm{~cm}$ ) e o tempo de reação máximo estudado (40 min) foram as variáveis com maior eficiência no tratamento das amostras analisadas. Além disso, os autores apontaram que o uso da assistência eletroquímica ao processo de coagulação/floculação é mais vantajoso e eficiente que o processo tradicional.

Os Processos Oxidativos Avançados (POA), baseiam-se na atuação de radicais com alto poder oxidante, geralmente a hidroxila ( $\mathrm{HO} \bullet$ ), com o intuito de degradar poluentes orgânicos, gerando produtos mais simples ou não poluentes, como água, sais inorgânicos ou dióxido de carbono $\left(\mathrm{CO}_{2}\right)$ (Brito et al., 2019). 0 mecanismo de abstração de hidrogênio é o mais comum quando se explica a interação entre o radical hidroxila e a matéria orgânica, Equações 4 e 5, onde, num meio aerado, há formação de radicais orgânicos, que podem formar substâncias mais simples após consecutivas etapas de reação, por meio de reações em cadeia; no entanto, devido a alta reatividade e baixa seletividade desse radical, deve-se atentar à formação de poluentes orgânicos persistentes (Araújo et al., 2016).

$$
\begin{array}{ll}
\mathrm{RH}+\mathrm{HO} \bullet \rightarrow \mathrm{R} \bullet+\mathrm{H}_{2} \mathrm{O} & \text { (Equação 4) } \\
\mathrm{R} \bullet+\mathrm{O}_{2} \rightarrow \mathrm{RO}_{2} \bullet & \text { (Equação 5) }
\end{array}
$$

Os POAs que se destacam são os químicos, foto-químicos, eletroquímicos e combinações entre esses (Araújo et al., 2016). O POA químico de maior interesse é o processo Fenton, que baseia-se na formação de radicais hidroxila via interação entre íons ferrosos, $\mathrm{Fe}^{2+}$, e agentes oxidantes fortes, como peróxido de hidrogênio, em meio aquoso (Equação 6) (Brito et al., 2019).

$$
\mathrm{Fe}^{2+}+\mathrm{H}_{2} \mathrm{O}_{2} \rightarrow \mathrm{Fe}^{3+}+\mathrm{HO} \bullet+\mathrm{OH}^{-}
$$

(Equação 6)

Baseado na Equação 6, nota-se que, além do radical hidroxila, há também a formação dos íons férricos e hidroxila. A interação entre os íons férricos e o peróxido de hidrogênio geram radicais hidroperoxila $\left(\mathrm{HO}_{2} \bullet\right.$ ), que é menos reativo que o $\mathrm{HO} \bullet$, sendo que os potenciais padrão de redução da $\mathrm{HO} \bullet$ e da $\mathrm{HO}_{2} \bullet, 2,80 \mathrm{~V}$ e $1,42 \mathrm{~V}$, respectivamente. Portanto, é comum adotar excesso de $\mathrm{Fe}^{2+}$ frente ao $\mathrm{H}_{2} \mathrm{O}_{2}$, de modo a maximizar a formação de $\mathrm{HO} \bullet$ em detrimento da formação de $\mathrm{HO}_{2} \bullet$ (Araújo et al., 2016).

No âmbito dos POA's, muitos resultados sobre têm mostrado a relevância dos métodos. Se tratando do processo Fenton, Nascimento (2020), Brito et al. (2019) e Vecchio (2019) propuseram-se a investigá-lo. Sob justificativas similares às de Vieira et al. (2015), Brito et al. (2019) investigaram a viabilidade da redução do teor de carbono orgânico da água residual do processo de produção de biodiesel de soja através do processo Fenton, utilizando $\mathrm{H}_{2} \mathrm{O}_{2}$ como agente oxidante, com proporção de $\mathrm{Fe}^{2+}: \mathrm{H}_{2} \mathrm{O}_{2}$ de $1: 50$ e com tempo de reação de 300 minutos. Desse sistema, os autores relataram um resultado pouco satisfatório, com uma média de 8,5\% de remoção após os 300 minutos de reação.

Outrora, utilizando o mesmo agente oxidante, Nascimento (2020) focou seus estudos no tratamento de água produzida, efluente gerado do processo de exploração de poços de petróleo e gás, e obteve resultados satisfatórios. Para a concentração de $\mathrm{H}_{2} \mathrm{O}_{2}$, foi utilizada uma proporção de 1:1 com o DQO do efluente tratado, além de proporções de $\mathrm{Fe}^{2+}: \mathrm{H}_{2} \mathrm{O}_{2}$ de $1: 5$ e 1:10, com tempo de reação de 60 minutos, seguidos de 30 minutos de decantação. Após o tempo de decantação, para as duas proporções de $\mathrm{Fe}^{2+}: \mathrm{H}_{2} \mathrm{O}_{2}$ estudadas não foram constatados $\mathrm{H}_{2} \mathrm{O}_{2}$ residual e redução de $100 \%$ do teor de óleos e graxas. Os ensaios de DQO mostraram uma redução de 95 e 100\% para os experimentos com proporções de $\mathrm{Fe}^{2+}: \mathrm{H}_{2} \mathrm{O}_{2}$ de 1:5 e 1:10, respectivamente; permitindo concluir que $\mathrm{o}$ 
aumento da concentração do agente oxidante contribui para o aumento da efetividade do tratamento do efluente, posto que o $\mathrm{H}_{2} \mathrm{O}_{2}$ residual, para os dois casos estudados, foram nulos.

Sendo a degradação da matéria orgânica pelo radical $\mathrm{HO} \bullet$ o objetivo principal dos POA's, estuda-se outros agentes oxidantes para esse fim, além do $\mathrm{H}_{2} \mathrm{O}_{2}$. Vecchio (2019) utilizou o ozônio $\left(\mathrm{O}_{3}\right)$ como agente oxidante para estudar a atuação do processo Fenton em efluentes com o corante Acid Green 25, os produtos farmacêuticos ampilicina e cloreto de benzalcônio, em reação de 30 minutos em diferentes $\mathrm{pH}, 3,7$ e 11. Dos três tipos de efluentes estudados, nos três valores de $\mathrm{pH}$, somente o efluente com cloreto de benzalcônio com pH 3 não se degrada completamente ao final de 30 min de reação, alcançando o valor de $80 \%$ aproximadamente. No geral, o pH 7 apresentou melhores resultados. Vale ressaltar que o uso do $\mathrm{O}_{3}$ como agente oxidante dispensou o envolvimento de outro composto, como os íons $\mathrm{Fe}^{2+}$ no caso do $\mathrm{H}_{2} \mathrm{O}_{2}$, o que pode tornar o primeiro tecnicamente mais viável que o segundo.

Tratando-se dos POAs fotoquímicos, têm-se o processo de fotólise de agentes oxidantes fortes e os processos de fotocatálise homogênea ou heterogênea (Silva Neto et al., 2020). Na fotólise, aplica-se radiação com energia suficiente para quebrar ligações químicas presentes nos agentes oxidantes fortes, como peróxido de hidrogênio ou ozônio, formando o radical hidroxila. No caso do peróxido de hidrogênio, radiação (hv) com comprimento de onda na faixa de 200 a $300 \mathrm{~nm}$ é capaz de quebrar a ligação entre os átomos de oxigênio da espécie, como mostra na Equação 7 (Araújo et al., 2016).

$$
\mathrm{H}_{2} \mathrm{O}_{2}+h v \rightarrow 2 \mathrm{HO} \bullet
$$

(Equação 7)

Os métodos de fotocatálise fundamentam-se na utilização da radiação para assistir o processo de catálise em um POA. Quando homogêneo, o sistema possui uma fase; quando heterogêneo, o sistema possui mais de uma fase. Na última, a utilização de catalisadores semicondutores, como o dióxido de titânio $\left(\mathrm{TiO}_{2}\right)$ é comum. Seu entendimento se dá devido ao fato desses condutores absorverem fótons, ocorrendo uma transição eletrônica, formando sítios no catalisador propensos a oxidar ou reduzir espécies (Silva Neto et al., 2020).

Nesse viés, Nascimento (2020) estudou o sistema UV/ $\mathrm{H}_{2} \mathrm{O}_{2}$ para o mesmo efluente supracitado em proporções de DQO do efluente e $\mathrm{H}_{2} \mathrm{O}_{2}$ de $1: 1,1: 2$ e 1:3, para tempos de reação de 1,2 e 3 h. Os resultados mostraram uma redução de óleos e graxas de mínimo de 80,7 \% (para proporção de DQO do efluente e $\mathrm{H}_{2} \mathrm{O}_{2}$ de $1: 3$ com tempo de reação de $1 \mathrm{~h}$ ) e menor redução de DQO de aproximadamente 53\% (para proporção de DQO do efluente e $\mathrm{H}_{2} \mathrm{O}_{2}$ de $1: 2$ com tempo de reação de $3 \mathrm{~h}$ ). Com base nesses resultados, e comparando com os obtidos pelo processo Fenton, Nascimento (2020) concluiu que o Fenton seria mais indicado que o Foto-Fenton, diante da facilidade de operação e baixo custo da primeira.

Ainda no âmbito dos processos assistidos via radiação, Brito et al. (2019) estudaram os efeitos da radiação UV e solar no processo Fenton. Além do Foto-Fenton, foram analisados os processos solar-foto-fenton (processo Fenton assistidos via radiações UV e solar) e puramente solar. 0 efluente analisado é o mesmo supramencionado, sendo os tempos de reação de 480 min para o foto-fenton e solar-foto-fenton, e de 660 min para o teste com radiação solar. 0 maior e o menor valor de degradação de carbono orgânico foi, em média, de $93,79 \%$ e $89,02 \%$, para os sistemas foto-fenton e solar-foto-fenton. Fundamentos nos resultados, os autores concluíram que o sistema que usa radiação puramente solar é promissor, devido sua simplicidade, disponibilidade e facilidade em adaptação em larga escala.

Já os POAs eletroquímicos podem ser entendidos como reações eletroquímicas com o intuito de formar o radical $\mathrm{HO} \bullet$, seja na superfície do eletrodo, a chamada oxidação 
anódica ou heterogênea, ou em solução, fenômeno chamado de homogênea (FARIA, 2018). Por se tratar de um procedimento eletroquímico, esse tipo de POA demanda aplicação de energia, tornando esse consumo uma das principais desvantagens desse método (Araújo et al., 2016; Faria, 2018).

Com base nisso, Faria (2018) estudou o tratamento de águas oriundas do tratamento de esgoto através de um reator eletroquímico, com eletrodos de malha de óxidos mistos de composição $\mathrm{NiCo}_{2} \mathrm{O}_{4}$, com o tempo de processo de $240 \mathrm{~min}$. Os resultados mostram uma redução de DQO de cerca de $80 \%$, mostrando a eficiência desse método.

Os POAs podem se combinar de modo a maximizar a degradação orgânica do poluente. Dentre essas combinações pode-se citar o processo foto-Fenton, eletro-Fenton, fotoeletro-Fenton. 0 primeiro é descrito pela Equação 6 com a presença da radiação, aumentando a velocidade da reação, maximizando a decomposição dos poluentes (Brito et al., 2019). O eletro-Fenton é um POA eletroquímico homogêneo, onde a atuação eletroquímica permite a formação de íons $\mathrm{Fe}^{2+}$ partindo de íons $\mathrm{Fe}^{3+}$, contribuindo para a formação de radicais $\mathrm{HO} \bullet$ (Araújo et al., 2016). O último, fotoeletro-Fenton, combina o processo Fenton, sob radiação e eletroquimicamente assistido, visando a otimização da degradação da matéria orgânica.

Objetivando confrontar a efetividade de diferentes métodos físicos e químicos, alguns autores realizam um estudo comparativo. Ferreira et al. (2019) compararam os processos de adsorção e o foto-fenton para tratamento de água residual de produção de biodiesel, proveniente de uma mistura de óleos de soja e sebo bovino. 0 processo fotofenton foi conduzido com as concentração de $15 \mathrm{mg} \cdot \mathrm{L}^{-1}$ de $\mathrm{Fe}^{2+}$ e de $250 \mathrm{mg} \cdot \mathrm{L}^{-1}$ para o $\mathrm{H}_{2} \mathrm{O}_{2}$. Já o ensaio de adsorção foi realizado em carvão ativado. Os experimentos tiveram tempos de 1 e $2 \mathrm{~h}$ de duração. Comparativamente, os ensaios de adsorção mostraram-se mais satisfatórios que os de foto-fenton, com reduções percentuais de poluente acima de $70 \%$ para 1 e $2 \mathrm{~h}$ de reação, em confronto com os valores de redução de 50 e $58 \%$ para os tempos de 1 e $2 \mathrm{~h}$, respectivamente, para o caso do foto-fenton. Os autores concluíram que o tipo de tratamento é um fator mais significativo que o tempo de processo.

\section{Conclusão}

Diante dos dados discutidos, nota-se que, para os métodos físico-químicos, tanto a adsorção, como os processos de agregação e os POA's têm exibidos resultados satisfatórios. Observa-se que a substituição do carvão ativado como adsorvente é pautado em muitos estudos, uma vez que o mesmo mostra-se dispendioso. Nesse viés, resultados promissores têm sido relatados, com o uso de materiais mais acessíveis e econômicos, como cana-de-açúcar e cinzas de casca de arroz.

No contexto dos métodos de agregação, resultados da literatura demonstram a relevância da presença do agente coagulante no sistema, bem como a agitação do sistema, com o intuito de promover as etapas intrínsecas desse método. Foi concluído que a escolha do agente coagulante deve ser feita com base no processo e nas condições finais de interesse para o efluente, considerando o custo como principal fator para a determinação de qual agente coagulante será utilizado. Foi constatado que coagulantes naturais são ambientalmente mais viáveis que os coagulantes químicos, e que apresentam resultados satisfatórios de tratamentos de efluentes, tornando possível a implementação dessa possibilidade. Foi percebido o interesse do estudo dos materiais dos eletrodos que compõe o sistema de eletrocoagulação/eletrofloculação, uma vez que foi discutido que esse fator afeta diretamente nos resultados do tratamento. Ademais, foi observada uma variada faixa de aplicação para os processos de eletrocoagulação/eletrofloculação.

Para o processo fenton, notou-se que o aumento da degradação da matéria orgânica ocorre com o aumento da concentração do agente oxidante, onde foi percebido que o $\mathrm{H}_{2} \mathrm{O}_{2}$ e o $\mathrm{O}_{3}$ demonstram resultados significativos. Para mais, a associação do 
processo fenton com radiação (UV ou solar) mostrou resultados superiores ao tratamento com o processo fenton, além de demonstrar a possibilidade da implementação do processo via radiação solar, recurso com alta disponibilidade e baixo custo. 0 tratamento com POA's eletroquimicamente amparados exibiu resultados satisfatórios.

\section{Conflito de interesses}

Os autores declaram não haver conflito de interesses.

\section{Referências}

Abreu, J. D.; Adam, C; Costa, A. F.; Marian, S.; Koslowski, L. A. D. Tratamento de efluente proveniente de serigrafia via eletrocoagulação. Brazilian Journal of Animal and Environmental Research, v. 2, n. 1, p. 547-556, 2019.

Andrade, A. N.; Blasques, R. V.; Villis, P. C. M.; Silva, D. F.; Gomes, W. C. Efficiency of electroflocculation in the treatment of water contaminated by organic waste. Revista Ambiente e Água, v. 15, n. 2, e2484, 2020. https://doi.org/10.4136/ambi-agua.2484

Araújo, K. S.; Antonelli, R.; Gaydeczka, B.; Granato, A. C.; Malpass, G. R. P. Processos oxidativos avançados: uma revisão de fundamentos e aplicações no tratamento de águas residuais urbanas e efluentes industriais. Revista Ambiente e Água, v. 11, n. 2, p. 387-401, 2016. https://doi.org/10.4136/ambi-agua.1862

Brasil. Resolução CONAMA no 430, de 13 de maio de 2011. Dispõe sobre as condições e padrões de lançamento de efluentes, complementa e altera a Resolução no 357, de 17 de março de 2005, do Conselho Nacional do Meio Ambiente - CONAMA. Disponível em: <http://www.mma.gov.br/port/conama/legiabre.cfm?codlegi=646>. Acesso em: 20 ago. 2020.

Brasil. Ministério do Meio Ambiente. Águas. Disponível em: <https://www.mma.gov.br/ agua.html>. Acesso em: 15 set. 2020.

Brito, G. F. S.; Oliveira, R.; Grisolia, C. K.; Guirra, L. S.; Weber, I. T.; Almeida, F. V. Evaluation of advanced oxidative processes in biodiesel wastewater treatment. Journal of Photochemistry \& Photobiology A: Chemistry, v. 375, p.85-90, 2019. https://doi.org/10.1016/j.jphotochem.2019.01.013

Faria, E. R. Confecção, caracterização e aplicação de eletrodos permeáveis a fluidos à base de óxidos metálicos mistos nos Processos Oxidativos Avançados Eletroquímicos. Murici: Universidade Federal dos Vales do Jequitinhonha e Mucuri, 2018. (Tese de doutorado).

Ferreira, T. F.; Ribeiro, C. B.; Gueri, M. V. D.; Buratto, W. G.; Pavanello, G. P.; Ayoub, J. P.; Besinella, G. B.; Stroparo, E. C. Estudo comparativo dos processos de adsorção no tratamento de efluente de biodiesel. Revista Gestão e Sustentabilidade Ambiental, v. 8, n. 1, p. 472-482, 2019. https://doi.org/10.19177/rgsa.v8e12019472-482

Gomes, M. C. R.; Mendonça, L. A. R.; Cavalcante, I. N. Mapeamento da vulnerabilidade e risco de poluição das águas subterrâneas na porção leste da Bacia Sedimentar do Araripe, Ceará, Brasil. Anuário do Instituto de Geociências - UFRJ, v. 41, n. 3, p. 252-259, 2018. https://doi.org/10.11137/2018_3_252_259

Kamali, M.; Alavi-Borazjani, S. A.; Khodaparast, Z.; Khalaj, M.; Jahanshahi, A.; Costa, E.; Capela, I. Additive and additive-free treatment technologies for pulp and paper mill effluents: Advances, challenges and opportunities. Water Resources and Industry, v. 21, 2019. https://doi.org/10.1016/j.wri.2019.100109 
Kieling, A. G. Adsorção de btex-benzeno, tolueno, etilbenzeno, e xileno: em cinza de casca de arroz e carvão ativado. Porto Alegre: Universidade Federal do Rio Grande do Sul, 2016. (Tese de doutorado).

Külzer, B. N.; Rodrigues, C. O. Geração e processos físico-químicos de tratamento de efluentes líquidos contendo pigmentos. HOLOS Environment, v. 16, n. 1, p. 58-69, 2016. https://doi.org/10.14295/holos.v16i1.10166

Miguel, F. C.; Silva, V. J. L.; Silva, E. M. B.; Andrade, A. M. C. Sementes de Moringa oleifera: coagulante natural utilizado no tratamento de efluente de lavanderia têxtil. Anais do Congresso Brasileiro de Gestão Ambiental e Sustentabilidade - Congestas 2017, v. 5, p. 535-542, 2017. Disponível em: <http://eventos.ecogestaobrasil.net/congestas2017/ trabalhos/pdf/congestas2017-et-03-020.pdf>. Acesso em: 25 abr. 2020.

Morais, N. W. S.; Santos, A. B. Análise dos padrões de lançamento de efluentes em corpos hídricos e de reuso de águas residuárias de diversos estados do Brasil. Revista DAE, v. 67, n. 215, p. 40-55, 2019.

Nascimento, J. L.; Magalhães Júnior, G. A.; Portela, R. R.; Sousa Neto, V. O.; Buarque, P. M. C.; Oliveira, M. S.; Moura, C. P. Aplicação de processo adsortivo para dessulfurização de combustíveis utilizando fibra de coco como adsorvente. Revista Matéria, v. 24, n. 3, 2019. https://doi.org/10.1590/s1517-707620190003.0731

Nascimento, K. S. Processos oxidativos avançados aplicados ao tratamento de água produzida. Rio de Janeiro: Universidade Federal do Rio de Janeiro, 2020. (Trabalho de conclusão de curso).

Ribeiro, D. B. Determinação das condições ótimas do processo de coagulação/ floculação para tratamento de efluente sintético de curtume. Porto Alegre: Universidade Federal do Rio Grande do Sul, 2018. (Trabalho de conclusão de curso).

Rocha, K. M.; Salamoni, S. P.; Santos, R. H.; Goldbach, A. Monitoramento e avaliação de parâmetros físico-químicos e microbiológicos de uma estação de tratamento de efluentes com sistema de lodos ativados em uma agroindustria no meio oeste de Santa Catarina. Revista de Engenharia Civil IMED, v. 3, n. 1, p. 25-36, 2016. https://doi.org/ 10.18256/2358-6508/rec-imed.v3n1p25-36

Rubilar, C.S. Clarificação química com coagulante PGo21Ca e fotocatálise heterogênea aplicada ao tratamento de efluente de curtume. Londrina: Universidade Tecnológica Federal do Paraná, 2017. (Dissertação de mestrado).

Seixas, F. L.; Gimenes, M. L.; Fernandes-Machado, N. R. C. Tratamento da vinhaça por adsorção em carvão de bagaço de cana-de-açúcar. Química Nova, v. 39, n. 2, p. 172-179, 2016. https://doi.org/10.5935/0100-4042.20160013

Silva Neto, I. F. S.; Souza, M. N. C.; Almeida, S. C. X. Degradação de corantes por processos fotocatalíticos no tratamento de efluentes industriais: uma revisão integrativa. Journal of Biology \& Pharmacy and Agricultural Management, v. 16, n. 4, pg. 365-363, 2020.

Silva, L. D.; Dantas, P. R.; Pereira Neto, L. M.; Arruda, V. C. M.; Tavares, R. G.; Silva, V. P. Eficiência da coagulação, floculação e decantação como tratamento primário de efluente têxtil. Revista GEAMA - Ciências Ambientais e Biotecnologia, v. 5, n. 1, p. 36-40, 2019.

Souza, P. C. Aplicação do processo de eletrocoagulação no tratamento de efluentes da indústria têxtil. Maringá: Universidade Estadual de Maringá, 2016. (Tese de doutorado).

Vecchio, P. D. Degradação de contaminantes de diferentes classes por processos oxidativos avançados: $\mathrm{O}_{3}, \mathrm{O}_{3} / \mathrm{UV}$ e $\mathrm{O}_{3} / \mathrm{Al}_{2} \mathrm{O}_{3}$. Porto Alegre: Universidade Federal do Rio Grande do Sul, 2019. (Dissertação de mestrado).

Rev. Bras. Gest. Amb. Sustent., 2020, vol. 7, n. 17, p. 1667-1678. 
Vieira, S. P.; Nascimento, F. A.; Braz, M. A.; Andrade Júnior, S. J.; Cavalcanti, L. A. P. Reuso de latinhas de alumínio recicláveis para tratamento de águas residuais da produção de biodiesel via eletrofloculação. Revista Brasileira de Gestão Ambiental e Sustentabilidade, v. 2, n. 3, p. 145-151, 2015. https://doi.org/10.21438/rbgas.020307

Worldometer - World Population by Year. 2020. Disponível em: <https://www.worldometers.info/world-population/world-population-by-year/>. Acesso em: 12 ago. 2020. 